\title{
COLOURS IN INTERIOR DECORATION AND VAASTU
}

\author{
Dr. Rekha Sharma \\ Asst. Prof.-Home Science \\ Govt. Girls P.G. College, Ujjain
}

Colours are nothing but lights of different frequencies and wavelengths. Every colour is a kind of radiation and so, colours used for walls do have a profound influence on people living in the space. Important aspects such as decision-making, cheerfulness, calmness and vibrancy can be achieved by the right use of colors. Vastu, which is based on principles of energies and radiations, gives precise guidelines about use of colours depending on the directional aspect and usage pattern of the room.

Colors according to Vaastu Shastra play an imperative role in bringing balance to our minds as well as bodies and to stimulate our energy. Therefore colors in a Home, Office, Factory, and Shop should be coordinated with the colors of respective planets and elements associated with different directions.Colors have a huge impact on our lives. Colors possess the power to lift our mood, raise our energy levels and increase our productivity. Vastu shastra prescribes certain floor and wall colors for the home to promote prosperity, good health and well-being. Colour scheme is an arrangement or pattern of colors or colored objects conceived of as forming an integrated whole or a combination of colours that has been chosen for a particular room

The meaning of vastu is dwelling, which is the home for god and humans. Vastu shastra is based on various energies that comes from atmosphere like solar energy from sun, cosmic energy, lunar energy, thermal energy, magnetic energy, light energy, wind energy. These energies can be balanced to enhance peace, prosperity and success. If a house is made according to these principles, the inmates enjoy all the happiness in lifeAccording to Vastu Shastra, different colors have different properties. It is by the aid of these properties that different colors can be chosen for different rooms. In general, green is considered to drive away anxiety, yellow improves memory, pink eases tension, and orange is good for the appetite.

Colors affect our body and mind very much. The purest and most thoughtful minds are those, which love colours. Colors according to Vaastu Shastra play a vital role in bringing balance to our minds as well as bodies and to stimulate our energy. Therefore colors in a Home, Office, Factory, and Shop should be coordinated with the colors of respective planets and elements associated with different directions .Our body absorbs colour energy through the vibration each colour gives off. Through colour, we receive all the energies we need to maintain a healthy body, mind, and soul. When something goes wrong or is out of balance, we can strengthen our energy centers through the conscious use of colour. Healing by exposing a diseased body to the right coloured light, is known as Colour Therapy, and was the first type of treatment therapy used by man. So even in ancient times, colours played an important role in Vaastu Shastra.

In Vedic periods, all colours were obtained from vegetables and flowers. Though the options were far less than what are available today, they were more permanent, soothing to the eye and more natural in appearance. Most essential features of life and human energy is greatly affected by color. As per Vastu brings prosperity, happiness and wealth.

In Nature, we see the following colors, namely Violet, Indigo, Blue, Green, Yellow, Orange, and Red ('VIBGYOR'), which are important tools to study Vastu subject. Our Planets, 'Kundalini 


\section{INTERNATIONAL JOURNAL of RESEARCH -GRANTHAALAYAH \\ A knowledge Repository}

Art

Chakras' shows these seven colors. These seven rays are primeval formative forces of Nature. Their presence and their combination indicate tangible information. A home that is built and decorated.

\section{VAASTU SHASTRA GUIDELINES FOR CHOOSING COLOURS FOR A HOUSE}

Zodiac Sign of the owner: In the first and most commonly followed method, the colour schemes are selected in conformance with the raashi (constellation / zodiac sign) of the owner to bring good luck and happiness.

$\begin{array}{ll}\text { Zodiac sign } & \text { Colors suggested } \\ \text { Aries } & \text { Coral red } \\ \text { Taurus } & \text { Milky white } \\ \text { Gemini } & \text { Green } \\ \text { Cancer } & \text { Rose red, pearl white } \\ \text { Leo } & \text { Ruby red, dim white } \\ \text { Virgo } & \text { Emerald green } \\ \text { Libra } & \text { Cement color, milky white } \\ \text { Scorpio } & \text { Pink, coral red } \\ \text { Sagittarius } & \text { Golden yellow } \\ \text { Capricorn } & \text { Dim red } \\ \text { Aquarius } & \text { Pink, blue } \\ \text { Pisces } & \text { Yellow, pure white }\end{array}$

Direction of the building: In the second method, the colour scheme is chosen according to the direction the building/room faces. Each direction is associated with a particular colour, which is actually the colour of the planet governing that direction.

East (Sun) - Brown

West (Saturn) - Grey

North (Mercury) - All greens

South (Mars) - Pink, coral red

North-East (Jupiter) - Golden yellow

South-West (Rahu) - Blue

South-East (Venus) - Silver white

North-West (Moon) - White

Colors can also be used based on directions. For instance, North- West rooms can be white, North rooms can be in light hues of Green, West rooms can be grays, South- East rooms can be varied colors, North-East rooms can be in shades and tones of Yellow like cream etc. and South rooms can be in shades and hues of Red. Colors can be used in a variety of ways. We can paint our walls with a range of colors. 


\section{VAASTU GUIDELINES FOR COLOUR SHADES FOR ROOMS OF A HOUSE}

Since blue is a cool shade and red is a warm colour, people often feel cold in a blue room and warm in a red room. It is the colour that makes them feel that way. So when painting rooms of a house, one must keep these points in mind and choose colours according to the amount of light and warmth in the room. Accordingly;

Room with poor daylight: It should be painted with light colours. Room with lot of natural light throughout the day: It can be painted in some deep color. Room that gets direct sunlight: It is not advisable to paint the walls yellow or peach. Room that has only a North window which admits cold light: Avoid the use of blue on the walls.

Ceilings: It is preferable to paint ceilings white since the ceiling temperature should be less than the human body temperature .

\section{VASTU GUIDELINES FOR THE USE OF 'COLOUR CONTRASTS' IN A HOUSE} Colour contrast is perhaps the most important factor in a composition or a design. Maximum contrast is obtained by the use of colours of extremely strong chromes. For example, a strong yellow on a black background is an excellent example of maximum visibility and is therefore used all over the world to highlight road signs, dividers and taxis. Explained here are the contrasts created by the use of different colours:

Black: Black makes colours both brighter and lighter in appearance. For example, in a painting, a face against jet black hair, appears more luminous for this reason.

Grey surrounding an intense colour: can increase the apparent colorfulness of the intense colour. It appears even brighter or brilliant.

Intense colour surrounding grey colour: can make the grey appear less grey and on the other hand, the greying of the bright colors. For example, grey surrounded with yellow will appear slightly blue. Grey surrounded by red, will appear slightly green etc.

Blending of colours: One must always bear in mind that no individual is completely white (good) or black (bad), but is an amalgam of the two- Grey. A sensible good blending can create a forceful creation.

We can wear clothes with colors of our preference; we can drink 'solarized' water in colored glasses. We can use curtains, carpets and furniture with different colors of our liking. Study rooms can be Green, kitchen and dining rooms can be Orange, meditation and prayer rooms can be white, living and conference rooms can be cream and hues of Yellow, and bedrooms can be Blue. Parents May perhaps, find rooms coloRed Blue for their children who tend to be aggressive. According to Vastu Shastra, white is a good color to be used in the East and North-West. Towards the West, Blue is beneficial. Green is recommended for North, pink and coral Red for South, different shades of Green for North- East, different shades of brown for South-West and silver white is good for South-East.

These colors portend well with the energy and radiations which flow in from the respective directions and hence, play a crucial role in enhancing harmony and positivity at home. Similarly, if a room has poor daylight, it should be painted in light color and if a room gets good amount of natural light throughout the day, it can be painted in some deep color. If a room has only a North 
window, which admits cold light, we should not use Blue on the walls. If a room gets much direct sunlight, it is not advisable to paint the walls Yellow or peach. It is nearly better to have ceilings white and the ceiling temperature should be less than the human body temperature. Some scholars suggest different color to the direction the building faces. They are really the colors of the planets governing these directions.

\section{WALL COLORS FOR DIFFERENT ROOMS}

1. Living Room- Yellow, blue, green, and beige are suitable colors for the living room as lighter and brighter colors are preferred in spaces where guests are entertained. These colors promote better relationships and an active environment.

2. Dining Room - Orange, peach, pink, green, and blue are the preferred colors for the dining room. Orange is the most beneficial of all wall colors for dining as it is said to improve appetite. Avoid black and all dull colors as it is a place for eating and digesting.

3. Kitchen - For the kitchen, white is the best color according to Vastu. As white is the color of purity and cleanliness, it is the best of all floor and wall colors for cooking. The kitchen should also have a dash of red to symbolise fire. It can be in the form of utensils or decorations. Blue can also be used in kitchens.

4. Puja Room/ Meditation Room - The colors yellow, sandalwood, blue, red, and green are all suitable for the meditation and Puja room. Yellow and sandalwood are the best followed by all the others. These colors are preferred because more sober colors are said to promote concentration and focus.

5. Bedroom - Pink, light green, light blue, and yellow can be used for painting the bedroom walls as these colors create a tranquil environment and promote good sleep. Pink is one of the most preferred Vastu colors for the bedroom. Yellow can be used for the elderly. Avoid dark blue and red for all bedroom home interiors

6. Children's Bedroom/Study Room - A child's room should be colored green as far as possible as green is the best color for children's activities like studying and sleeping. Blue can be used if the child is aggressive.

7. Bathroom - White, black, white, grey and shades of pink can be used for the bathroom. White is the best color followed by combinations of black, white and grey.Apart from these, Vastu also stipulates certain laws on how to choose colors based on the house owner's zodiac sign and the direction or orientation of the house. It is always advisable to seek the help of Vastu consultants before making any changes to your home.

\section{REFERENCES}

$1 \quad$ Anna Hong Rutt, (1969), Home Furnishing, Willey Eastern Pvt. Ltd. New Delhi.

2 Chaudhary, Ramchandra,(2003), VastuShastra tatha Hum aur humara bhavan, Amit Pocket Books, Jalandhar.

$3 \quad$ Interior Designing Handbook, 1994, Cheerman Ltd.,London.

$4 \quad$ Khandelwal, Bhavani.,(2001), Vastu Evam Pyramid, Sahityagar, Jaipur.

5 Lamba, Manoj Kumar.,(2004), Sampurna Vastushastra, Sahni Publications, Delhi. 
6 Nagar, Dr. Bela., (2004), Housing, Space \& Management, University Book House Pvt. Ltd., Jaipur.

$7 \quad$ Nagar, Dr. Bela., (2005), Family Resourse Management and Interior Decoration, University Book House Pvt. Ltd., Jaipur

8 Patni, Manju.,(1999), Aawas Grihsajja evam Gharelu Upakarn, Shiva Prakashan, Indore .

$9 \quad$ Poori, Dr. Umesh., (2003), Vastukala aur Bhavan Nirman, $5^{\text {th }}$ Edition, Randheer Prakashan, Haridwar.

10 Tessi Agan, M. S., (1970), The House Its Plan and Use, Oxford IBH Publishing Co., New Delhi.

11 www.indiamart.com.

12 www.vastudoshremedies.com

$13 w w w . s e r e n e i n t e r i o r s . c o m$.

improving the luck of a site and residence in which we live Following colours are, therefore, proposed for improving 'Vastu' of a building.

- Purple - Purple, deep red, or plum is an equally auspicious colour. It is said to inspire respect.

- Yellow - Yellow or gold stands for Power. Yellow gives a sense of tolerance, patience, and wisdom gained from past experience.

- Green - Green represents Tranquility, Hope, and Freshness. In plants and vegetation, green indicates good and healthy earth energies.

- Blue - Blue or indigo symbolizes Spring, New Growth, and Hope. However, blue is also a cold, secondary and mourning colour.

- Blue - Green - Blue - green mint, or aqua are more Auspicious than indigo as they are more closely aligned with the colours of nature and spring. In general, vitality represents verdant youth.

- Black - On the positive side, black - or any dark colour - gives a feeling of depth, both in mood and perspective. Yet black indicates a Lack of Hope, and it may make us feel "Dark" low and Depressed.

- Gray - Gray is an ambiguous - or gray area. To some, gray, like a dismal cloudy day, keynotes Frustration and Hopelessness . To other, it is positive and signifies Balance and the Resolution.

- Brown - Brown gives us a heavy feeling, the colour can be used to create a stable, established impression and a sense of the passage of time. It symbolizes the Depth and Elegancy.

- TAN - Tan or caf represents a new, successful beginning. Out of seeming Hopelessness, a new possibility arises.

- Orange - Orange, as a mixture of red and yellow and yellow, is Auspicious and is imbued with the characteristics of Happiness and Power.

- Pink - Pink represents Love and Pure Feelings, Joy, Happiness, and Romance.

Peach - It is the colour representing Attraction and Love.

Note: This research paper is based on secondary data selected from following references on internet. 